\title{
Effect of a preseating cementation protocol on the retention of implant restorations using a definitive cement
}

\author{
Rodrigo A Jiménez, Karla García-Camacho, Shirley Mora-Loaiza, Mauricio Quesada-Solís, \\ Tatiana Vargas-Koudriavtsev
}

\section{ABSTRACT}

Purpose: This investigation analyzed the effects of a preseating cementation protocol on the amount of cement excess at the crown margin and its associated tensile load using a glass ionomer definitive cement.

Materials and Methods: The independent variable in this study was the cementation technique. The first protocol involved a conventional cementation procedure and the second one preseating on an abutment replica. Ten metallic copings were cemented using a definitive cement on ten implant abutments for each cementation protocol. Cement excess at the margin was weighted (mg), and axial tensile load was measured $24 \mathrm{~h}$ after cementation. Results were statistically analyzed using linear regression and one-way analysis of variance $(\alpha=0.05)$.

Results: The cementation protocol with preseating resulted in a significantly smaller amount of cement excess at the crown margin $(P \leq 0.001)$ without detriment on the tensile resistance when compared to the experimental group without preseating $(P=0.41)$. Linear regression failed to prove any correlation between the amount of cement excess and tensile load necessary for dislodgement.

Conclusions: A preseating protocol can be performed when using a definitive cement. This procedure reduces significantly the amount of cement excess at the margin while maintaining an acceptable tensile load resistance.

KEY WORDS: Cementation, dental restoration, implant crowns, implant restorations, preseating

\section{INTRODUCTION}

It has been reported that 2.3 million implant-supported crowns are placed every year. ${ }^{[1]}$ These restorations can be constructed using a screw retained or a cemented connection protocol. There has been a rapid switch

Department of Prosthodontics, School of Dentistry, University of Costa Rica, San José, Costa Rica

Address for correspondence: Dr. Tatiana Vargas-Koudriavtsev, School of Dentistry, University of Costa Rica, San José, Costa Rica. E-mail: tatiana.vargas_k@ucr.ac.cr

\begin{tabular}{|l|l|}
\hline \multicolumn{2}{|c|}{ Access this article online } \\
\hline Quick Response Code: & Website: \\
\hline & www.jdionline.org \\
\hline & \\
\hline
\end{tabular}

toward cement-retained prostheses ${ }^{[2]}$ even though there is a high risk of severe peri-implant inflammation and bone loss. ${ }^{[3]}$ Furthermore, one study showed that excess cement was not completely removed in $81 \%$ of examined cemented cases. Furthermore, approximately $80 \%$ of peri-implantitis cases are caused by bacterial colonization of extruded cement. ${ }^{[4]}$ This is the reason why all efforts to prevent excess cement at the margins should be enforced. Several approaches have been

This is an open access journal, and articles are distributed under the terms of the Creative Commons Attribution-NonCommercial-ShareAlike 4.0 License, which allows others to remix, tweak, and build upon the work non-commercially, as long as appropriate credit is given and the new creations are licensed under the identical terms.

For reprints contact: reprints@medknow.com

How to cite this article: Jiménez RA, Garcia-Camacho K, Mora-Loaiza S, Quesada-Solís M, Vargas-Koudriavtsev T. Effect of a preseating cementation protocol on the retention of implant restorations using a definitive cement. J Dent Implant 2019;9:20-3. 
attempted including placing vents on the crowns ${ }^{[5]}$ and keeping cement reservoirs under the restorations. ${ }^{[6]}$ Furthermore, a popular technique consists of using an abutment duplicate to seat the cement-filled restoration just before placing it at the final position in the mouth, and in this way, a thin layer of cement is obtained all throughout the restoration intaglio. ${ }^{[7,8]}$

A previous study compared several methods for reducing excess cement at the margins. ${ }^{[9]}$ It also correlated retention of the restoration with each method. During the experiments, it was evident that preseating the restoration, filled with temporary cement on an abutment analog, produced the least amount of excess cement extrusion at the margins. However, it also showed a marked decrease in retention. For this reason, the aim of the present in vitro study is to evaluate the mechanical behavior of the samples using a preseating cementation protocol and definitive cement.

\section{MATERIALS AND METHODS}

This research protocol was approved by the Research Commission of the School of Dentistry at the University of Costa Rica. Methodology was described in a previously published article. ${ }^{[9]}$

Briefly, ten straight implant abutments (GingiHue Biomet 3i, APP454G) were screwed on ten implant analogs (Biomet 3i, ILAW5). These were fixed on acrylic resin blocks with the same path of insertion. The screw access holes were sealed with a light-cured resin (Revotek LC, GC America).

Metal copings with an incisal loop were fabricated in nonprecious alloy (Argeloy NP, Argen) for each abutment. Each coping was cemented with a definitive glass ionomer cement (RelyX Luting 2, 3M ESPE, lot N860413) with either one of two protocols $(n=10)$, whose order was assigned in a randomized manner. One protocol involved preseating of the coping with the unset cement on an abutment replica in acrylic resin (Pattern Resin LS, GC America) before seating the coping on the definitive abutment [Figure 1]. The other protocol was a regular cementing technique and did not involve preseating. In both cases, the screw access was closed.

The definitive cement was mixed with a plastic spatula and was dispensed in a plastic measuring device, which was weighed to standardize the amount of luting agent $(60 \mathrm{mg})$.

After the coping was positioned on the implant abutment and seated into place, a load of $5 \mathrm{~kg}$ was maintained for $5 \mathrm{~min}$. Following this, the cement excess was removed from the margin with a scalpel blade and

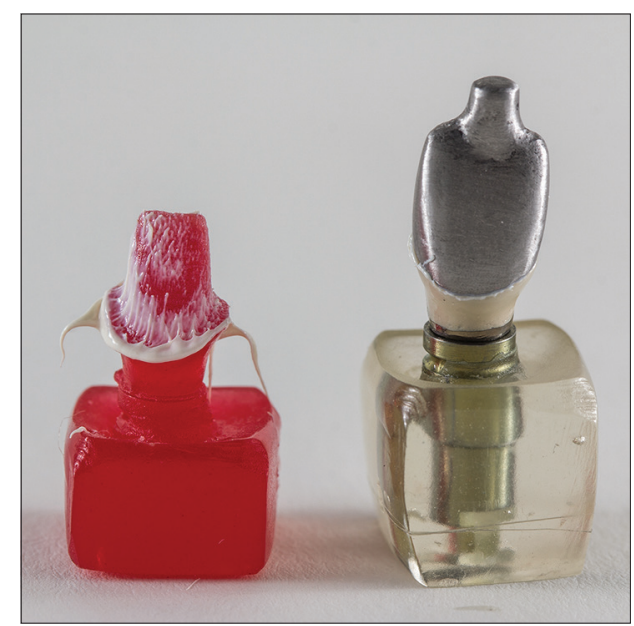

Figure 1: Preseating cementation protocol on abutment replica

was weighed on an analytical scale (Gemini Analytical Balance, Meldrum Scale Company). The specimens were then stored in distilled water at $32^{\circ} \mathrm{C}$ for $24 \mathrm{~h}$. Tensile load tests were performed with a universal testing machine (H10KS, Tinius Olsen) at a crosshead speed of $1 \mathrm{~mm} / \mathrm{min}$, and the cement fail load $(\mathrm{kg})$ was recorded.

The researcher responsible for measuring cement excess and tensile load fail did not know to which experimental group belonged the specimen, therefore this study is double-blind. Statistical analysis included the descriptive statistics as well as one-way analysis of variance (ANOVA; $P \leq 0.05$ ) to analyze the effect of the cementation protocols on the cement excess and tensile load failure. Furthermore, a linear regression was carried out to analyze the relationship between the two dependent variables.

\section{RESULTS}

The amount of cement excess extruded at the margins varied significantly among the two experimental groups $(P \leq 0.05)$. Specimens that were not cemented with a preseating protocol had in average $62.2 \mathrm{mg}$ of cement excess at the margins, whereas their counterparts had only $4.45 \mathrm{mg}$ of cement extruded [Figure 2].

Regarding the tensile load necessary for failure, a Levene test showed that an ANOVA was possible $(P=0.961)$. The results of one-way ANOVA depicted that there is no significant difference between the experimental groups [Table 1] which can be explained with the increased standard deviations within each group [Figure 3].

The linear regression failed to show any correlation between the amount of cement excess and the resistance to tensile dislodgement [Table 1]. 
Jiménez, et al.: Preseating cementation protocol and implant crown retention

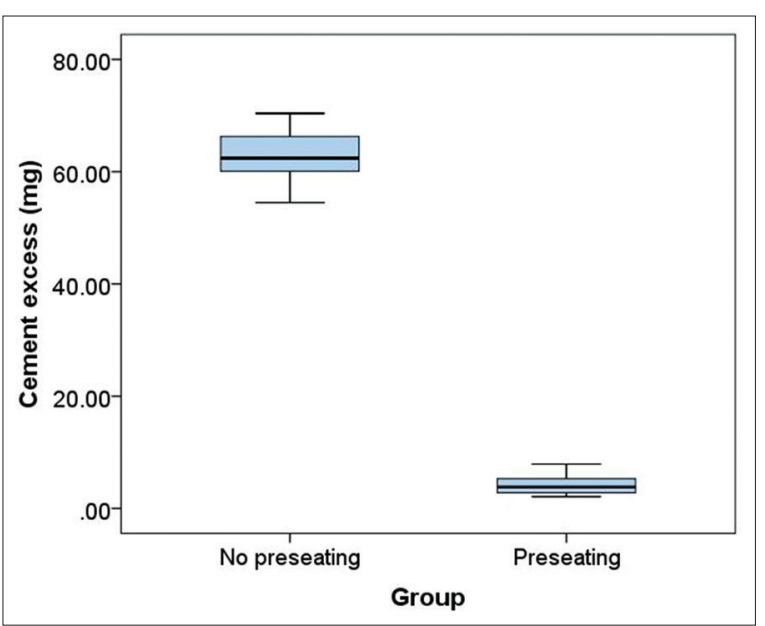

Figure 2: Amount (mg) of excess cement extruded at the abutment margin. Vertical bars on boxes = standard deviations

\begin{tabular}{|c|c|}
\hline Variable/test & Significance \\
\hline ANOVA for cement excess & 0.000 \\
\hline ANOVA for tensile force & 0.412 \\
\hline Linear regression cement excess/tensile force & 0.410 \\
\hline
\end{tabular}

\section{DISCUSSION}

It is a well-known fact that cement excess at the subgingival margins of implant restorations can be very detrimental to peri-implant health. ${ }^{[10]}$ Every effort must be made to prevent it or to adequately remove it but is very difficult to see and eliminate in depths greater than $3 \mathrm{~mm} \cdot{ }^{[7]}$ For this reason, several techniques have been developed to reduce the amount of excess cement. ${ }^{[5-8]}$ Some of these methods have been previously evaluated by the authors ${ }^{[9]}$ and the preseating protocol significantly proved to be the most efficient in reducing cement extrusion. It also showed statistically significant lower retentive strength values, using temporary cement (Freegenol, GC America).

Temporary cements have often been used in implant dentistry to allow for retrievability of the restoration. ${ }^{[11]}$ This would be ideal when removal of the restoration is needed for reservicing, repairing, replacing, and salvaging it in the event of a biological or technical complication. ${ }^{[12]}$ However, the restoration should not be dislodged during normal functional forces, and this is a critical balance. On one hand, the restoration should be luted lightly enough to be easily removed without damage if the need arises, and on the other hand, it should be able to withstand all the functional stresses without being decemented. A special problem arises when a restoration is cemented, and the abutment screw loosens. Ideally, the crown

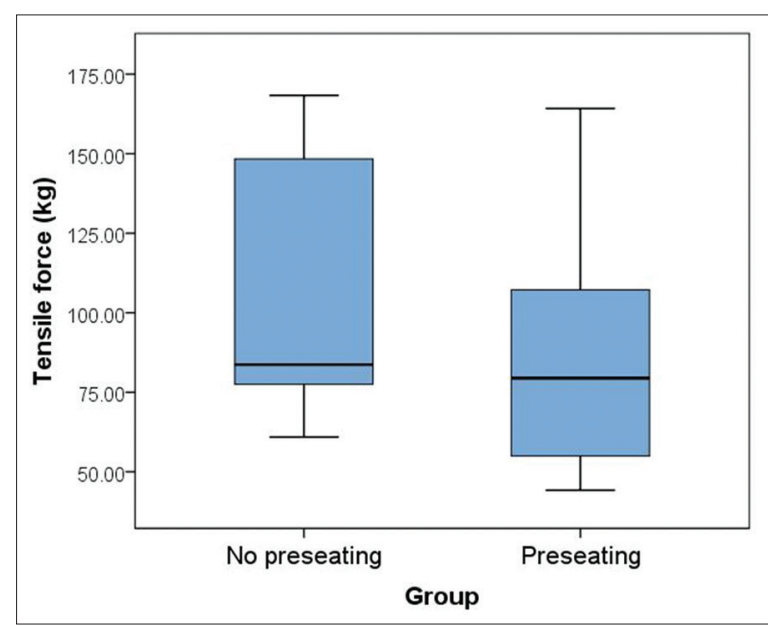

Figure 3: Retentive strength values $(\mathrm{kg})$. Vertical bars on boxes $=$ standard deviations

should be removed, the screw retorqued or replaced, and the crown cemented again. If the crown cannot be removed, it may have to be destroyed. It is reported that a very common problem of implant-supported single crowns is abutment screw loosening ( $5.8 \%$ after 5 years).${ }^{[13]}$ However, this same systematic literature review cites that almost as frequently, loss of retention of cemented crowns (5.5\%) becomes another technical complication. These facts confirm the delicate equilibrium between retention and retrievability.

Retention of the restoration can be influenced by the height and taper of implant abutments and the type of cement. ${ }^{[14,15]}$ Cement film thickness has also an influence on the retention of implant-cemented crowns. However, we are comparing this retention with excess cement as related with different cementation protocols and not retention per SE. In this respect, we found that there is no statistically significant difference between groups where preseating was used and groups where it was not. We also found that preseating significantly reduces excess cement at the abutment-coping margin.

There is no information in the literature regarding the minimum amount of retention of any restoration to clinically perform in an acceptable way. This is due to considerable amounts of variables that may make a restoration loose in one patient and not in another. They include occlusal forces, parafunctional habits, opposing dentition, and type of food consumed. Furthermore, the geometric characteristics of the abutment previously described will increase or decrease retention of the same cement.

\section{CONCLUSIONS}

Within the limitations of this in vitro study, it can be concluded that when cementing metallic crowns on

Journal of Dental Implants | Volume 9 | Issue 1 | January-June 2019 


\section{Jiménez, et al.: Preseating cementation protocol and implant crown retention}

titanium implant abutments with glass ionomer cement, a preseating protocol can be employed since it reduces significantly the amount of cement excess at the margin while providing sufficient retention for the restoration.

\section{Acknowledgments}

The authors would like to acknowledge the Macro Research Program of the Dental Faculty at the University of Costa Rica for providing a platform for the development of this project.

This project was partially financed by the University of Costa Rica.

\section{Financial support and sponsorship}

This project was partially financed by the University of Costa Rica.

\section{Conflicts of interest}

There are no conflicts of interest.

\section{REFERENCES}

1. American College of Prosthodontists. Facts and Figures. American College of Prosthodontists; 13 July, 2018. Available from: https://www.gotoapro.org/facts-figures/. [Last accessed on on 2019 Jan 10].

2. Shetty S, Garg A, Shenoy KK. Principles of screw - Retained and cement - Retained fixed implant prosthesis: A critical review. J Interdiscip Dent 2014;4:123-29.

3. Pauletto N, Lahiffe BJ, Walton JN. Complications associated with excess cement around crowns on osseointegrated implants: A clinical report. Int J Oral Maxillofac Implants 1999;14:865-8.

4. Wilson TG Jr. The positive relationship between excess cement and peri-implant disease: A prospective clinical endoscopic study. J Periodontol 2009;80:1388-92.
5. Patel D, Invest JC, Tredwin CJ, Setchell DJ, Moles DR. An analysis of the effect of a vent hole on excess cement expressed at the crown-abutment margin for cement-retained implant crowns. J Prosthodont 2009;18:54-9.

6. Wadhwani C, Piñeyro A, Hess T, Zhang H, Chung KH. Effect of implant abutment modification on the extrusion of excess cement at the crown-abutment margin for cement-retained implant restorations. Int J Oral Maxillofac Implants 2011;26:1241-6.

7. Dumbrigue HB, Abanomi AA, Cheng LL. Techniques to minimize excess luting agent in cement-retained implant restorations. J Prosthet Dent 2002;87:112-4.

8. Wadhwani C, Piñeyro A. Technique for controlling the cement for an implant crown. J Prosthet Dent 2009;102:57-8.

9. Jimenez RA, Vargas-Koudriavtsev T. Effect of preseating, screw access opening, and vent holes on extrusion of excess cement at the crown-abutment margin and associated tensile force for cement-retained implant restorations. Int J Oral Maxillofac Implants 2016;31:807-12.

10. Gapski R, Neugeboren N, Pomeranz AZ, Reissner MW. Endosseous implant failure influenced by crown cementation: A clinical case report. Int J Oral Maxillofac Implants 2008;23:943-6.

11. Akça K, Iplikçioğlu H, Cehreli MC. Comparison of uniaxial resistance forces of cements used with implant-supported crowns. Int J Oral Maxillofac Implants 2002;17:536-42.

12. Gervais MJ, Wilson PR. A rationale for retrievability of fixed, implant-supported prostheses: A complication-based analysis. Int J Prosthodont 2007;20:13-24.

13. Jung RE, Pjetursson BE, Glauser R, Zembic A, Zwahlen $M$, Lang NP. A systematic review of the 5-year survival and complication rates of implant-supported single crowns. Clin Oral Implants Res 2008;19:119-30.

14. Bresciano M, Schierano G, Manzella C, Screti A, Bignardi C, Preti G. Retention of luting agents on implant abutments of different height and taper. Clin Oral Implants Res 2005;16:594-8.

15. Mehl C, Harder S, Shahriari A, Steiner M, Kern M. Influence of abutment height and thermocycling on retrievability of cemented implant-supported crowns. Int J Oral Maxillofac Implants 2012;27:1106-15. 